\section{ÁREAS DE INTERÉS PARA LA GESTIÓN PÚBLICA: APROXIMACIONES PARA EL DISEÑO DE UNA METODOLOGÍA DE FOCALIZACIÓN TERRITORIAL ${ }^{1}$}

\author{
Mónica Alejandra Bustos Peñafiel ${ }^{2}$
}

\section{Resumen}

Con el propósito de facilitar el proceso de selección y priorización de los territorios a intervenir por el Programa de Recuperación de Barrios del Ministerio de Vivienda y Urbanismo, se ha desarrollado una metodología de focalización territorial que busca identificar áreas de interés para la gestión pública.

Dicho desafío no sólo resulta consistente con la necesidad de establecer criterios objetivos, cuantificables y transparentes para orientar la inversión en la escala barrial, sino que tiene relevancia con miras a construir unidades de gestión urbana mayor, que permitan una visión integral de los

\section{AREAS OF INTEREST FOR PUBLIC MANAGEMENT: APPROACHES TO THE DESIGN OF A TERRITORIAL- BASED METHODOLOGY ${ }^{1}$}

Mónica Alejandra Bustos Peñafiel ${ }^{2}$

\section{Abstract}

In order to facilitate the process for the selection and prioritization of territories that requires intervention by the Neighborhood Recovery Program - promoted by the Ministry of Housing and Urban Development-, a territorial-based methodology has been developed to identify the areas of interest for public management.

Such a challenge is not only consistent with the need to establish objective, quantifiable and transparent criteria to guide neighborhoodscaled investment, but also with the creation of major urban management entities intended 
territorios a partir de una planificación concertada y estratégica.

Con este objetivo, el presente artículo da cuenta de las primeras aproximaciones desarrolladas para el diseño de una metodología de focalización territorial, exponiendo las posibilidades que nos devela su aplicación, al contribuir tanto en los procesos de regeneración como en las posibilidades de igualar las condiciones urbanas de los distintos territorios.

PALABRAS CLAVES: FOCALIZACIÓN TERRITORIAL; VULNERABILIDAD SOCIAL; INDICADORES URBANOS; ZONAS PRIORITARIAS; ESCALA INTERMEDIA.

Recibido: 18-02-2015

Aceptado: 16-05-2016

1 Propuesta metodológica desarrollada y aplicada para identificar áreas de vulnerabilidad para la selección de barrios del Programa de Recuperación de Barrios del Ministerio de Vivienda y Urbanismo.

2 Chile. Doctora en Urbanismo y Ordenación Territorial, Universidad Politécnica de Catalunya. Arquitecta, Universidad de Chile. Encargada del Área de Estudios de la Secretaría Ejecutiva de Desarrollo de Barrios, División de Desarrollo Urbano del Ministerio de Vivienda y Urbanismo. Correo electrónico: mbustos@minvu.cl. to provide a comprehensive view of territories according to concerted and strategic planning.

With the above objective in mind, this paper offers the first approaches to the design of a territorial-based methodology by setting out the possibilities of its implementation and contribution to regeneration processes and equalization of the urban conditions of different territories.

\section{KEYWORDS: TERRITORIAL-BASED APPROACH; SOCIAL VULNERABILITY; URBAN INDICATORS; PRIORITY AREAS; INTERMEDIATE SCALE.}

Received: 18-02-2015.

Accepted: 16-05-2016.

1 This is a methodological proposal developed and implemented to identify vulnerable areas within the context of the Neighborhood Recovery Program, which is promoted by the Ministry of Housing and Urban Development.

2 Chile. PhD in Urban and Territorial Planning, Technical University of Catalonia. Architect, University of Chile. Supervisor, Study Department at the Executive Secretariat for Neighborhood Development, Urban Development Division, Ministry of Housing and Urban Planning. Email: mbustos@minvu.cl. 


\section{Introducción}

A lo largo de más de un siglo, Chile ha logrado materializar diversas políticas públicas en materia habitacional, sin embargo, en las últimas décadas es posible constatar un cambio en la política sectorial, que está pasando de una mirada centrada en el déficit habitacional a un enfoque orientado a mejorar la calidad de vida de los habitantes a través del acceso a viviendas dignas, barrios equipados y ciudades integradas.

En este contexto, si bien desde finales de la década de 1990 para el Ministerio de Vivienda y Urbanismo se venía instalando la preocupación por el alto nivel de obsolescencia del parque habitacional construido sólo décadas antes, así como por las problemáticas sociales vinculadas a él, la creación del Programa de Recuperación de Barrios en el año 2006 pasa a ser uno de los hechos más significativos, marcando un punto de inflexión fundamental en su quehacer.

Promoviendo la integración social y la equidad urbana, el programa focaliza su acción en revertir procesos asociados al deterioro físico y la vulnerabilidad social, por medio de un trabajo que apuesta por el fortalecimiento del tejido social a través de un proceso participativo que involucra a la comunidad y el municipio, centrando su objetivo en la recuperación integral de unidades territoriales de 'escala barrial', a través del mejoramiento y dotación de los espacios públicos existentes.

El programa es desarrollado en su fase piloto entre los años 2006-2010, iniciando posteriormente una segunda fase, en la que, a partir de los diversos aprendizajes y evaluaciones derivados de su implementación, aparece la necesidad de avanzar en la identificación objetiva de los barrios a intervenir, con el propósito de priorizar los territorios con mayor vulnerabilidad.

Sin embargo, entendiendo que las ciudades son sistemas complejos conformados por unidades de diferente tamaño y jerarquía, y entre las cuales se reconocen vínculos económicos, sociales, políticos, culturales e identitarios, simultáneamente se evidencia que la identificación de los barrios aptos para la intervención, así como la elaboración de los planes y estrategias adecuadas de regeneración, deben estar guiadas por criterios y consideraciones interescalares que promuevan acciones capaces de articular los cambios a nivel local con el desarrollo de las ciudades, sus entornos urbanos y tejidos intermedios.

Sobre esta discusión, el Área de Estudios de la Secretaría Ejecutiva del Programa de Recuperación de Barrios del Ministerio de Vivienda y Urbanismo se plantea el desafío de avanzar en el diseño de una metodología de focalización territorial, que permita por un lado, identificar y priorizar los territorios 
que presentan condiciones de vulnerabilidad social y deterioro urbano, colaborando por otro lado en la necesidad de construir unidades funcionales a la planificación estratégica de las ciudades, en coherencia con una visión integral e interescalar de los territorios.

De acuerdo a estos objetivos, con el fin de colaborar en disminuir la alta segregación urbana que presentan nuestras ciudades a nivel nacional, en primera instancia el artículo expone la discusión centrada en el fenómeno de la desigualdad a nivel físico-espacial como social y sus implicancias en el desarrollo humano, indagando posteriormente, a través de distintos autores, en la necesidad de abordar la ciudad no sólo mediante intervenciones de carácter puntual como el Programa de Recuperación de Barrios, sino que considerando el reconocimiento de territorios urbanos de escala mayor.

En segunda instancia, el artículo da a conocer las distintas fases que implicó el diseño y aplicación de la metodología, permitiendo reconocer y sancionar dos tipos de unidades estratégicas de nivel intermedio entre la escala macro de planificación (la ciudad o sistema urbano) y la escala micro (el barrio o conjunto urbano), denominadas respectivamente como 'áreas de vulnerabilidad' y 'zonas prioritarias'. Se detalla así el proceso de selección de indicadores de focalización que han permitido reconocer aquellas áreas de concentración de vulnerabilidad, exponiendo posteriormente el proceso metodológico desarrollado para la configuración de las 'zonas prioritarias', como unidades de gestión urbana. Así, mientras las 'áreas de vulnerabilidad' son resultado del diagnóstico urbano que permite identificarlas, las 'zonas prioritarias' se constituyen como unidades de planificación e intervención de escala intermedia, colaborando en la mirada interescalar que requieren los procesos de regeneración urbana.

Finalmente, desde la sistematización de la metodología, el artículo da cuenta de sus principales hallazgos, exponiendo las nuevas y diversas posibilidades que nos devela su uso. Se reconoce así la contribución clave que puede llegar a tener su aplicación como herramienta en los procesos de regeneración urbana, en tanto, al favorecer un enfoque integral e interescalar de los territorios, revela su potencialidad y aporte en el desafío de igualar las condiciones urbanas en las distintas ciudades chilenas. 


\section{La escala barrial como unidad de gestión urbana}

El Programa de Recuperación de Barrios instala la 'escala barrial' como nueva unidad de gestión de la política pública, mediante territorios de acción que por su tamaño se ubican entre la vivienda y la ciudad.

Si hasta ese momento se había abordado la vivienda como unidad de gestión en la que debía dialogar con la familia como actor clave, con la 'escala barrial' se debe comenzar a dialogar con un tejido social existente, determinando una nueva forma de trabajo que necesariamente requerirá de la participación vecinal como principio básico de intervención.

Con un claro enfoque territorial, que centra su quehacer sobre la ciudad ya construida, la implementación del programa, a través de la 'escala barrial' como nueva unidad de gestión urbana para el ministerio, viene a plantear la oportunidad de abordar la inversión de manera estratégica y focalizada, jerarquizando aquellos sectores más vulnerables social y físicamente.

\section{Concursabilidad como criterio de selección y la eficiencia en el uso de la inversión pública}

Asegurando la presencia del programa en todas las ciudades cabeceras regionales, en su fase piloto el proceso de selección de 200 barrios $^{3}$ a intervenir se efectuó en dos etapas. En una primera instancia focalizando su actuar en aquellas comunas con más de 70.000 o 100.000 habitantes por conurbanización, que tuvieran el $10 \%$ de la población en situación de pobreza ${ }^{4}$. Posterior a ello, conformando mesas regionales por distintos actores, se identificaron los barrios según condiciones de deterioro urbano o déficit de infraestructura y problemas de vulnerabilidad social.

Sin embargo, los distintos estudios y evaluaciones del programa apuntan hacia la necesidad de establecer criterios respecto a selección y distribución de la inversión pública. Entre éstos, la Dirección de

3 Localizados en 80 comunas de las 15 regiones del país, el programa piloto se inicia atendiendo a una población que alcanza los 550.000 habitantes, que representan el $3 \%$ de la población nacional y el $10 \%$ de la población pobre e indigente de las comunas atendidas.

4 Dirección de Presupuestos, 2010, p. 5. 
Presupuesto ${ }^{5}$ en su evaluación de programas gubernamentales establece la necesidad de "definir con parámetros objetivos las variables que determinarán los estándares mínimos para la futura selección de los barrios", señalando que es "necesario incorporar criterios de concursabilidad"6.

Dado el riesgo que implica discriminar determinados polígonos respecto de otros, las evaluaciones plantean la necesidad de incorporar criterios de focalización y priorización que sean claros y objetivos. De hecho, dentro de las conclusiones del 'Estudio de evaluación del Programa Quiero mi Barrio: Una propuesta metodológica'7, referidas al proceso de selección de los barrios, se indica que "en la medida en que el universo de barrios potenciales de la intervención del programa es significativamente mayor que el número de barrios efectivamente seleccionados sobre los cuales se invertirán recursos excepcionales, con el objetivo de brindar la legitimidad necesaria, la selección de los barrios a intervenir por el programa deberá tener un sólido fundamento, basado en la vulnerabilidad social y el deterioro urbano". Esta situación también se expresa en el estudio de evaluación

5 La Dirección de Presupuestos DIPRES en el organismo evaluador de los programas y políticas ministeriales, velando por el quehacer estratégico de la institución a través del correcto establecimiento de la misión, objetivos estratégicos, productos (bienes y servicios) estratégicos y clientes / usuarios / beneficiarios, que permitan orientar la formulación del presupuesto.

6 Dirección de Presupuestos, op. cit., p. 84.

7 Alcalá Consultores, 2010, p. 89. realizado por SUR Profesionales, donde se señala que "la selección de los barrios debe atender al criterio ético redistributivo de acceso a bienestar y poder de las comunidades con mayores niveles de deterioro y exclusión, con el criterio de eficiencia en el uso de la inversión fiscal"".

Estas recomendaciones, sumadas al objetivo final de disminuir la fuerte segregación que enfrentan nuestras ciudades igualando las condiciones urbanas de los distintos territorios que la conforman, determinan la decisión de comenzar a trabajar en la formulación de una metodología adecuada que colabore de manera más precisa en la priorización de las áreas a intervenir.

8 Sur Profesionales Consultores, 2009, p. 23. 


\section{Segregación residencial versus vulnerabilidad social: la expresión territorial de la desigualdad}

La segregación residencial es el reflejo territorial de los efectos que tiene la desigualdad en las ciudades, estableciendo una vinculación directa entre la organización social y espacial de los territorios urbanos.

Aunque existe consenso de que un enfoque basado exclusivamente en la pobreza de ingresos o en las necesidades básicas insatisfechas -referido a mínimos estándares de habitabilidad y acceso a servicios- resulta una definición incompleta, la diferenciación de la población según su condición socioeconómica es una de las dimensiones más frecuentes de la segregación, característica que, a su vez, se corresponde con el acceso desigual a infraestructura, equipamiento, servicios y espacios públicos.

De acuerdo a ello, complementando la definición de segregación residencial, resulta fundamental acercarse a la definición de vulnerabilidad social, condición que para Castel corresponde al riesgo de desestabilización de las personas frente a su capacidad de sostener las redes de relación que aseguran su inserción en un medio. De aquí que para el autor, la vulnerabilidad social está determinada "no sólo por la precarización del empleo, sino que también por la fragilización de los soportes relacionales que aseguran su inserción en un medio en el que resulte humano vivir"9.

Desde esta perspectiva resulta evidente la vinculación entre vulnerabilidad social y exclusión social, en tanto, si nos referimos a la noción de segregación residencial, ésta describirá una situación donde la desigualdad de los individuos y poblaciones se ve forzada por procesos de concentración y separación del territorio. De hecho, aunque por sí sola la pobreza es un concepto limitado para describir las condiciones de precariedad material y exclusión que experimenta una parte importante de los habitantes de las ciudades, en la mayoría de los casos es el indicador común del deterioro urbano, manifestándose con mucha más fuerza en sectores periféricos, asociados habitualmente a extensos complejos de vivienda, definiendo así un patrón de distribución del deterioro ${ }^{10}$.

En Chile, según reconoce la nueva Política Nacional de Desarrollo Urbano (PNDU), "la mayoría de las grandes ciudades presentan altos grados de desigualdad urbana y segregación social, con sectores con altos niveles de concentración de pobreza,

9 Castel, 1995, p. 2.

10 Schiappacasse y Müller, 2008, p. 82-91. 
inseguridad, falta de acceso a servicios públicos y escasa conectividad"11, fenómeno que además está marcado por la formación de grandes extensiones territoriales ocupadas masivamente por conjuntos de vivienda social, emplazadas en la periferia.

De acuerdo a este diagnóstico, es preciso reconocer cómo la localización residencial en las ciudades señala desventajas concretas para acceder a diferentes recursos y activos urbanos, incidiendo en la reproducción de las desigualdades. En el caso chileno, este fenómeno se ve aún más justificado por los efectos derivados de la aplicación de la Política Nacional de Desarrollo Urbano de 1979, que, de la mano del traspaso de las funciones de diseñador y constructor de vivienda social al privado, a través de una amplia política de subsidios habitacionales, fue determinando la formación de un patrón común de la periferia ${ }^{12}$.

Marcada por una ocupación territorial segregada del resto de la ciudad, a partir de este momento, la formación de las nuevas áreas residenciales de vivienda social se fueron configurando de manera fragmentada como islas urbanas con deficiente accesibilidad, con tejidos residenciales morfológicamente homogéneos, sin acceso a servicios y equipamientos, sin estructura urbana y espacios públicos consolidados ${ }^{13}$, efectos que sin duda han estimulado con muchísima más fuerza el deterioro de la periferia, conformando significativos bolsones de pobreza asociados estructuralmente a una fuerte vulnerabilidad social.

Un hecho que viene a constatar esta situación es que un 58,5\% de la totalidad de los 200 barrios que formaron parte de la experiencia piloto del programa presenta una localización periférica o suburbana, seguido de un $35,5 \%$ de barrios de localización periurbana. Esta realidad, cruzada con el año de construcción de los barrios, está directamente vinculada a que la mayor cantidad de barrios localizados en la periferia han sido construidos posterior al año 1979 (38\%), siendo los que presentan problemáticas asociadas principalmente a estructuras urbanas sin consolidación, con alto estado de deterioro y carentes de espacios públicos.

Analizar esta tendencia es significativo ya que caracteriza claramente las problemáticas a las que se ven enfrentados los barrios que interviene el programa, donde los más antiguos generalmente presentan problemáticas ligadas al deterioro de estructuras urbanas consolidadas, y los barrios más recientes, problemáticas ligadas a materias como accesibilidad, ausencia de estructura urbana y carencia de áreas verdes y servicios (figura 1), así como una concentración de diversas problemáticas

11 Giménez y Ugarte, 2014, p. 23.

12 Bustos, 2006, p. 151.

13 Ibíd. 


\section{FIGURA 1. DETERIOROS DE LOS ENTORNOS DE LA VIVIENDA SOCIAL CONSTRUIDA EN LA DÉCADA DE LOS}

OCHENTA.

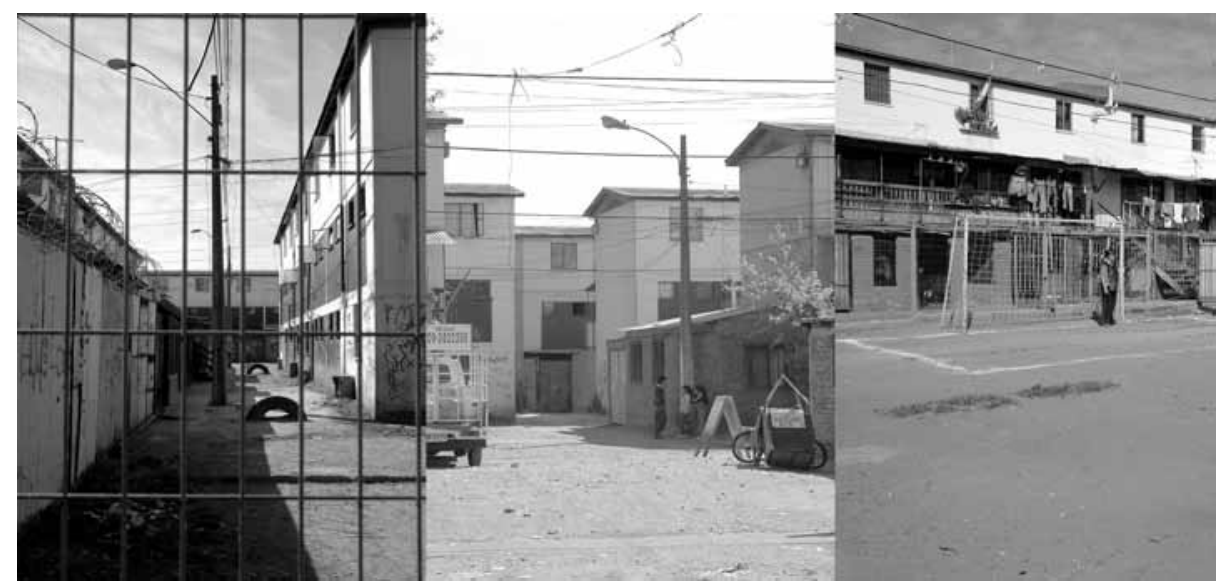

Fuente: elaboración propia.

sociales como delincuencia, micro y narcotráfico, hacinamiento, etc. De hecho, según se expresa en el libro Los con Techo: un desafio para la política de vivienda social ${ }^{14}$, esta realidad nos devela que el "64,5\% de la población que habita viviendas sociales si pudiera las abandonaría y casi el $90 \%$ se siente avergonzado del lugar donde vive".

En este contexto, frente a la responsabilidad que le compete al ministerio como institución pública, se justifica la decisión de establecer como innovación a la selección de los barrios un enfoque objetivo que permita, a través del uso de indicadores, hacer una aproximación a aquellos territorios donde la pobreza se encuentra concentrada en grandes paños residenciales con alto deterioro y déficit urbano, identificando zonas de "carácter prioritario", cuyas problemáticas, por su gravedad en relación a la situación de segregación urbana que sufren,

14 Rodríguez y Sugranyes, 2005, p. 73. 
representan los objetivos que espera alcanzar el Programa de Recuperación de Barrios ${ }^{15}$.

\section{Zonas prioritarias como nueva unidad de gestión urbana de escala intermedia}

Si bien los barrios atendidos en el marco del programa piloto se definen como "territorios delimitados, conformados por espacios con identidad, con límites distinguibles para sus habitantes y los externos, con similitud en cuanto a condiciones de vivienda, equipamiento y servicios, afectados por procesos de exclusión social, deterioro físico y vulnerabilidad social"16, a la luz de los aprendizajes y evaluaciones se pudo constatar que en la mayoría de los casos, muchas de sus principales problemáticas tienen su raíz en el entorno urbano mayor que las comprende.

15 Desde este mismo enfoque, considerando el actual escenario de fuerte desigualdad territorial, la nueva política nacional de desarrollo urbano pone énfasis en que el Estado tiene una responsabilidad importante en la reducción de la segregación residencial y el desarrollo armónico e integrado de las ciudades, planteando como propósito la necesidad de "velar por que nuestras ciudades sean lugares inclusivos, donde las personas estén y se sientan protegidas e incorporadas a los beneficios urbanos: acceso a los espacios públicos, educación, salud, trabajo, seguridad, interacción social, movilidad y transporte, cultura, deporte y esparcimiento", con lo que "este objetivo debe ser de prioridad nacional". Giménez y Ugarte, op. cit., p. 23.

Ministerio de Vivienda y Urbanismo, 2009.
Esta realidad vino a plantear un nuevo desafío, al entender que en muchos casos es en el contexto urbano de emplazamiento de los barrios donde está el origen de sus principales problemáticas, evidenciando la necesidad de "abordar la complejidad del territorio de manera sistémica"17 y articulada con todas sus escalas.

Se entiende entonces que un barrio no puede ser abordado de forma endógena al interior de sus límites, sino que su intervención debe considerar el entorno urbano sobre el cual se encuentra emplazado. Esto implica reconocer que los barrios no son polígonos configurados a partir de una delimitación física administrativa, sino que sus fronteras naturalmente se extienden hacia territorios de mayor envergadura, característica que llama la atención respecto de la necesidad de impulsar los procesos de regeneración urbana al alero de una estrategia integral que considere distintos enfoques e inversiones complementarias, pero que sobre todo

17 Schiappacasse y Müller, op. cit., p. 82-91. 
mire a la ciudad desde una perspectiva interescalar. Dicho enfoque busca reconocer la complejidad de los sistemas urbanos, enfrentando el desafío de diseñar intervenciones integrales y coordinadas en diferentes niveles, con el propósito de considerar los fenómenos o carencias de los barrios en sus entornos urbanos de soporte.

Bajo estos postulados aparece la necesidad de diseñar una metodología de focalización territorial que permita, por un lado, colaborar en el proceso de selección de los barrios, pero al mismo tiempo que favorezca la identificación y configuración de territorios de gestión urbana de escala intermedia entre el barrio y la ciudad. Entendidas como nuevas unidades de planificación e intervención, dichas unidades han sido denominadas como 'zonas prioritarias'.

\section{¿POR QUÉ TRABAJAR EN ZONAS PRIORITARIAS?}

Entendida como la plataforma urbana de los barrios, la configuración de 'zonas prioritarias' no sólo resulta consistente con la necesidad de establecer criterios objetivos y transparentes para orientar la inversión ministerial en la escala barrial, acercándonos a las que deben ser las principales áreas de interés para la gestión e inversión ministerial, sino que tiene relevancia con miras a construir unidades funcionales a la planificación estratégica de las ciudades, en coherencia con una visión integral e interescalar de los territorios.

En consecuencia, la configuración de una 'zona prioritaria' presenta la oportunidad de resolver, bajo una mirada interescalar e intersectorial, diversas problemáticas de escala urbana que afectan directamente la recuperación de los barrios. A partir de la comprensión estratégica de su contexto, su configuración como nueva unidad de gestión urbana de escala intermedia entrega la posibilidad de articular múltiples inversiones favoreciendo la generación de sinergias entre distintos programas e inversiones, públicos o privados.

La necesidad de abordar una perspectiva interescalar surge de distintas limitaciones y demandas del programa piloto que ya se dejan ver en sus propias evaluaciones, como por ejemplo la evaluación de la Dirección de Presupuesto, que apuntando a una serie de recomendaciones señala que "se recomienda redefinir el actual programa, de modo que el concepto de barrio sea lo suficientemente flexible como para aglomerar áreas de interés urbanas en base a un plan maestro de acción territorial"18.

Interesante es dar cuenta de la recomendación que ya desde los inicios del programa realiza el experto internacional en recuperación de barrios Frank Samol, quien, desde la perspectiva de establecer una política pública de recuperación de

18 Dirección de Presupuestos, op. cit., p. 14. 
barrios que institucionalice el programa como línea permanente, advierte la necesidad de "reforzar los vínculos de los barrios con el resto de la ciudad y con el concepto de la integración / inclusión social"19, agregando que "limitarse a intervenciones en barrios con bordes fijos, sin considerar suficientemente las interrelaciones entre el mismo y la ciudad puede generar una consolidación de la segregación social y espacial"20.

De esta forma, Samol advierte que el modo de intervención y operación del Programa Barrios se enfoca básicamente a barrios definidos por criterios internos como nivel de pobreza, vulnerabilidad, importancia política, etc., los que no necesariamente toman en cuenta los vínculos y relaciones entre el barrio y el resto de la ciudad. Señala así que las intervenciones se concentran en 'polígonos cerrados' que parecieran no generar sinergias con los barrios vecinos ni considerar suficientemente el desafío de promover la integración del barrio en el tejido urbano, con lo que se trataría de intervenciones puntuales y aisladas no sólo de la ciudad sino que incluso de sus propias comunas ${ }^{21}$.

Recomienda para ello considerar "una ampliación de enfoque de las intervenciones a futuro, de modo que vayan más allá de los límites del barrio, incluyendo intervenciones en zonas urbanas vecinas,

\footnotetext{
19 Samol, 2008, p. 13.

20 Ibíd., p. 14.

21 Ibíd., p. 13.
}

desde una perspectiva de desarrollo urbano más integradora", planteando en este contexto "la idea de establecer como precondición, o incluso como requisito para la participación de barrios en futuras intervenciones de fomento, la preparación de planes de desarrollo urbano integrados para todo el municipio en conexión con la ciudad"22.

En esta línea, respecto a la pregunta de si el programa dio respuesta al problema identificado, el "Estudio de evaluación del Programa Quiero mi Barrio: Una propuesta metodológica" precisa que "si bien existe un cambio muy significativo en los barrios intervenidos, los logros son parciales respecto de un objetivo [la recuperación de barrios] que por su envergadura requiere la incorporación de planes mayores de gestión urbana y la coordinación de obras de escala intercomunal, que apoyen los proyectos de integración en su área de influencia mayor"23.

De hecho, los resultados de la encuesta aplicada por el estudio a los vecinos del programa en relación a las condiciones de vida y percepción de la ciudad, es decir en relación al acceso a oportunidades, revela problemas de integración urbana que no se modifican con las obras de escala barrial del programa, sino que con infraestructura de redes y subcentros de escala urbana. De ahí que, sobre

\footnotetext{
22 Ibíd., p. 14.

23 Alcalá Consultores, op. cit., p. 63.
} 
el proceso de selección de los barrios, un aspecto adicional que el estudio señala es "la necesidad de realizar dicha selección en el contexto de una visión urbana más amplia"24, planteando que esta mirada también deberá ser válida para la determinación de los proyectos a desarrollar, considerando las distintas expresiones que deben tenerse en cuenta en función del tamaño de las ciudades ${ }^{25}$.

Desde el enfoque teórico, por su parte, la actual discusión en materia de planificación urbana también cuestiona los instrumentos clásicos de planeamiento como herramientas para regular ciertos fenómenos espaciales que enfrenta hoy la ciudad, tan diferentes a los que dieron lugar a su aparición ${ }^{26}$. En este sentido, Jeréz ${ }^{27}$ sostiene que no se trata tanto de un cuestionamiento en sí o de alguna de sus formaciones históricas, sino de su pertinencia en la sociedad emergente, donde la respuesta más interesante tal vez sea la que reconoce la dificultad del desafío, planteando "la exigencia de una revisión disciplinar continua frente a unos problemas urbanísticos siempre cambiantes".

24 Ibíd., p. 197.

25 Considera, por ejemplo en el caso de las ciudades metropolitanas, que lo principal de la relación con el entorno urbano es la influencia de éste sobre el barrio y, por lo tanto, será necesario estudiar qué intervenciones de un ámbito mayor se requieren para modificar las limitaciones del barrio.

26 Jerez, 2008, p. 100

27 Ibíd.
Solá-Morales ${ }^{28}$ comenta que "con frecuencia estos planes han acabado por perder la riqueza y la variedad de los fenómenos que previamente habían querido definir [...]. La complejidad interior se simplifica cambiando las medidas y la óptica, limitándola a ciertos sistemas (parámetros) de gran dimensión (infraestructuras, centralidades, espacios verdes, zonas)," planteando que "tal vez hace falta comenzar a pensar de otra manera la 'ordenación' de la ciudad".

Portas ${ }^{29}$ plantea la necesidad de una revisión disciplinar, "proponiendo la sustitución del actual sistema de planeamiento -rígidamente jerarquizado y normativo- por otro que contemple distintas formas de intervención interactivas, es decir, planes o proyectos con alcance estratégico, sin precedencias establecidas, que acojan nuevas nociones de regulación y geometría variables ligadas al reconocimiento de la administración de la incertidumbre espacial y temporal del plan".

Es así que, centrada en la estrecha relación que existe entre el deterioro físico-espacial y la vulnerabilidad social, uno de los aspectos relevantes que

\footnotetext{
28 Sola-Morales, 2008, p. 122

29 Jerez, op. cit., p. 101.
} 
viene a plantear el trabajo en 'zonas prioritarias' es la posibilidad y oportunidad de abordar el territorio de manera estratégica, a través de unidades de intervención de escala intermedia. Abordarlos desde diversas perspectivas de forma integral.

Si bien la formación de 'zonas prioritarias' como nueva unidad de gestión viene a complejizar el trabajo de regeneración urbana, la posibilidad de abordar el territorio desde una mirada interescalar presenta la oportunidad de desarrollar soluciones integrales desde la vivienda, el barrio, sus entornos urbanos y la ciudad, considerando simultáneamente diversas problemáticas.

El trabajo focalizado por medio de 'zona prioritaria', a partir de unidades estratégicas de intervención urbana, podrá colaborar en el acabado urbano de la ciudad, contribuyendo a la regeneración del territorio interescalarmente. Esta mirada significará la riqueza del proyecto en la construcción de la ciudad, en tanto las escalas referidas a la vivienda, el barrio y sus entornos necesariamente requerirán considerar directamente a los ciudadanos en la toma de decisiones, integralidad que podrá verse reflejada en el conjunto final de la ciudad.

La oportunidad de trabajar articuladamente en una escala de intervención territorial menor que la ciudad en su conjunto, nos entrega la posibilidad de llegar a resolver las complejidades urbanas reales más sentidas de manera puntual, revirtiendo lo planteado por Solà-Molares ${ }^{30}$ respecto a que en muchos casos, como consecuencia de la planificación tradicional, "la complejidad interior de las ciudades se ha simplificado, limitándose a ciertos parámetros de gran dimensión", instalando así la necesidad de considerar, "por encima de las estructuras, las 'cosas'; a cambio de las infraestructuras, las intraestructuras. Antes de lo grueso, lo fibroso. Más que el esqueleto, el tejido".

Es en este punto en el que se centra la propuesta metodológica, es decir, en la necesidad de mirar el territorio más allá de las infraestructuras urbanas o del polígono del barrio, abordando desde una perspectiva integral su carácter interescalar e intersectorial, a través de la 'zona prioritaria' como pieza urbana mayor. De esta forma, a la hora de proponer un trabajo de regeneración urbana al interior de una 'zona prioritaria', la mirada interescalar se presenta como la oportunidad de resolver problemáticas comunes a diversos barrios a partir de un proyecto de escala urbana, así como a nivel intersectorial plantea la posibilidad de articular recursos, permitiendo establecer acciones concertadas entre distintos actores, generando vínculos y acuerdos que sean establecidos a nivel de la 'zona prioritaria'.

30 Sola-Morales, op. cit., p. 126. 


\section{La focalización territorial como nuevo desafío}

La necesidad de diseñar una metodología de focalización territorial surge con la intención expresa de avanzar en un enfoque de vulnerabilidad social anclado al territorio, identificando aquellas áreas que por su condición de vulnerabilidad deben ser de interés para la gestión pública.

La complejidad de la propuesta estuvo centrada en la tarea de construir una herramienta que permitiera establecer una referencia diagnóstica, con el fin de identificar y priorizar aquellas áreas que requieren iniciar un proceso de regeneración urbana. Con este objetivo, desde la definición de criterios objetivos y estandarizados, en primera instancia se trabajó en la selección de indicadores que nos acercaran a las áreas de vulnerabilidad social, déficit y deterioro urbano, para posteriormente georreferenciarlos en el territorio, logrando visualizar espacialmente la vulnerabilidad de las ciudades.

\section{INDICADORES URBANOS COMO INSTRUMENTO DE FOCALIZACIÓN TERRITORIAL}

El trabajo con indicadores cuantitativos se presenta como un instrumento clave que puede colaborar en el ejercicio de hacer una lectura objetiva del territorio, dando cuenta de las áreas de concentración de vulnerabilidad social y deterioro urbano. Dicha lectura se transforma en oportunidad al develar de manera objetiva las desigualdades, problemáticas y oportunidades del territorio. Se evidencian así, los contrastes existentes, la concurrencia o ausencia de inversión, permitiendo dimensionar las distintas necesidades de la planificación urbana.

Con el objetivo de establecer una distribución equitativa de los atributos urbanos en el territorio, el trabajo con indicadores como instrumento de focalización urbana permitirá favorecer la toma de decisiones adecuadas de intervención. En consecuencia, la posibilidad de visualizar espacialmente los indicadores en el territorio permitirá la definición de lineamientos objetivos a la hora de focalizar la inversión, priorizar las acciones y formular las coordinaciones adecuadas entre los distintos actores y programas, colaborando en la definición de soluciones estratégicas e integrales.

\section{DEFINICIÓN DE INDICADORES}

De acuerdo a los objetivos y a la metodología de doble dimensión física y social del Programa de Recuperación de Barrios, definir exhaustivamente los indicadores fue de alta importancia. Bajo el criterio de que los barrios seleccionados estuvieran localizados en aquellos territorios que presentaran mayor concentración de vulnerabilidad social y deterioro urbano, los indicadores debían permitir una aproximación tanto al deterioro físico-espacial 
como a la vulnerabilidad socioeconómica del territorio.

Sin embargo, fue más fácil acceder a indicadores de caracterización socioeconómica que a aquellos referidos a aspectos urbanos como déficit de áreas verdes, déficit de equipamientos y servicios, calidad de los espacios públicos, pavimentación, iluminación, mobiliario urbano, etc., en tanto, éstos no han sido catastrados homogéneamente para todas las comunas.

Con base en esta realidad, estableciendo como criterio la necesidad de información transversal para todas las ciudades del país, a la hora de determinar los indicadores con los cuales trabajar se optó por aquellos que estuvieran disponibles a nivel nacional y que pudieran ser comparables en el tiempo.

En consecuencia, dada la inexistencia de indicadores de deterioro urbano propiamente tal para todas las ciudades a nivel de manzana censal, de acuerdo a la información estadística georreferenciada y disponible, se definieron cuatro atributos o indicadores claves como variables proxy que describieran situaciones relevantes de vulnerabilidad social y habitacional, en tanto dichos indicadores, además de evidenciar territorialmente la segregación residencial, presentaban un estrecho y estructural vínculo con el deterioro urbano.

La fuente de información que se utilizó para obtener los indicadores se extrajo del Censo de
Población y Vivienda del año 2002. Esta decisión se fundamenta en una serie de ventajas, entre las que destaca la desagregación espacial que permite obtener datos a nivel de manzanas o la universalidad de tener el mismo dato en todo el territorio en una única temporalidad, características que a su vez -tomando la precaución de seleccionar indicadores relativamente estables y persistentes en el tiempo- favorecerán la comparabilidad interurbana de la información generada.

Una vez identificados, cada uno de los indicadores seleccionados en esta propuesta fue asociado a distintos umbrales, considerando en cada caso el porcentaje de hogares por manzana según la capacidad de aproximarse a la vulnerabilidad (tabla 1).

De acuerdo al umbral asignado, cada indicador fue georreferenciado y espacializado mediante el modelo de densidad Kernell, el que calcula en una superficie determinada una concentración de entidades en función de su localización y algún atributo puntual de ésta. Definiendo un radio de búsqueda específico para cada entidad, se calcula la existencia de proximidades entre sí, tomando en cuenta que a mayor cercanía entre puntos el valor de la densidad es multiplicado. El resultado del proceso es una nueva representación espacial en formato raster que grafica en "mapas de calor" los sectores con mayor o menor densidad según el atributo seleccionado. La aplicación de este ejercicio, basado en la interpolación de las variables mediante la 
TABLA 1. UMBRALES DEFINIDOS PARA CADA UNO DE LOS INDICADORES PARCIALES.

\begin{tabular}{|c|c|c|}
\hline Variable & INDICADOR & $\begin{array}{c}\text { Umbral } \\
\text { (\% de hogares por manzana) }\end{array}$ \\
\hline \multirow[t]{2}{*}{ Deterioro del entorno } & $\begin{array}{c}\underline{\text { Hacinamiento }} \\
\text { (con } 3 \text { o más personas por dormitorio) }\end{array}$ & $10 \%$ o más \\
\hline & $\begin{array}{l}\text { Viviendas precarias y/o con déficit cualitativo } \\
\text { (viviendas de calidad recuperable e irrecuperable) }\end{array}$ & $5 \%$ o más \\
\hline \multirow{2}{*}{ Vulnerabilidad social } & $\begin{array}{l}\text { Baja escolaridad del jefe de hogar } \\
\text { (media incompleta o menos) }\end{array}$ & $30 \%$ o más \\
\hline & $\begin{array}{l}\text { Jóvenes desempleados sobre el total de jóvenes eco- } \\
\text { nómicamente activos ( } 15 \text { a } 29 \text { años) }\end{array}$ & $\begin{array}{c}5 \% \text { o más } \\
\text { (en manzanas con } 4 \text { o más jóvenes } \\
\text { económicamente activos) }\end{array}$ \\
\hline
\end{tabular}

Fuente: Área de Estudios SEDB / Comisión de Estudios Habitacionales y Urbanos. MINVU, 2011.

asignación de valores continuos a través de todo el territorio (figura 3), permitió identificar las principales concentraciones de cada uno de los indicadores en el contexto de cada una de las ciudades (figura 2).

Posteriormente se realizó la construcción de un índice sintético conjunto (basado en los 4 indicadores) en la escala de la manzana, constituyendo el denominado índice de vulnerabilidad territorial.

Aplicable a cada uno de los territorios, el índice de vulnerabilidad territorial fue espacializado nuevamente a través del modelo de densidad Kernell (figura 3), ejercicio que, mediante la construcción de cartografías detalladas, permitió identificar las principales concentraciones de vulnerabilidad existentes para cada una de las ciudades (figura 4).

De esta forma, a través del análisis de las densidades de concentración se comienzan a configurar lo que hemos denominado 'áreas de vulnerabilidad territorial'. Expresadas como un área difusa, homogénea y continua, caracterizada por concentrar altos niveles de vulnerabilidad, cada mancha fue definiendo su extensión geográfica representando con las tonalidades más oscuras la concentración del índice en sus zonas más críticas. En consecuencia, la concentración de vulnerabilidad se va evidenciando producto de la existencia de un conjunto de manzanas que agrupadas presentaron, de 


\section{FIGURA 2. MAPAS DE CONCENTRACIÓN PARA LA CIUDAD DE ARICA SEGÚN LA INTERPOLACIÓN DE CADA INDICADOR}
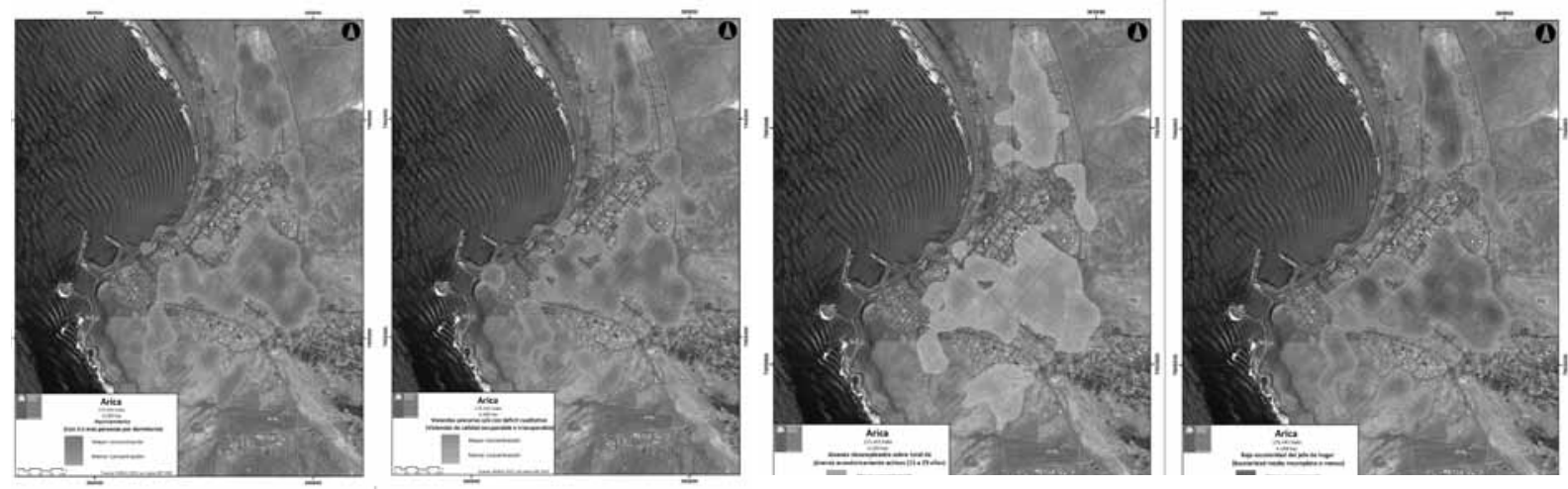

Fuente: Área de Estudios, Secretaría Ejecutiva de Desarrollo de Barrios. MINVU, 2011.

manera simultánea, valores superiores al umbral crítico establecido para cada indicador.

\section{LA CONFIGURACIÓN DE 'ZONAS PRIORITARIAS'}

Una vez identificada el 'área de vulnerabilidad territorial' en cada ciudad, considerando que sus fronteras son difusas en el espacio, fue necesario establecer límites operativos con el objetivo de materializar el trabajo en ella. A partir de ese momento se configura la 'zona prioritaria' como una unidad de gestión urbana de escala intermedia. En esta línea, importante es aclarar que una ciudad podrá llegar a configurar más de una 'zona prioritaria', dependiendo de la localización, tamaño, dispersión y existencia de una o varias 'áreas de vulnerabilidad' en un mismo territorio.

\section{DEFINICIÓN DE LOS LÍMITES OPERATIVOS}

Los límites operativos hacen referencia al contorno de una 'zona prioritaria' y son definidos desde una mirada estratégica, con el objetivo de configurar una pieza urbana de planificación con bordes claros que la contengan y delimiten territorialmente. De esta forma, las zonas prioritarias se constituyen a partir de (o de manera concurrente a) una o más áreas de vulnerabilidad a través de límites 


\section{FIGURA 3. INTERPOLACIÓN DEL ÍNDICE SINTÉTICO MEDIANTE LA ASIGNACIÓN DE VALORES CONTINUOS EN EL TERRITORIO.}

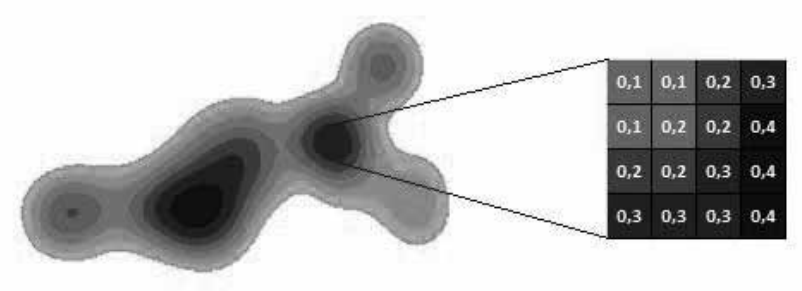

Fuente: Área de Estudios, Secretaría Ejecutiva de Desarrollo de Barrios. MINVU, 2012.

definidos operativamente, en atención a distintos criterios como calles o ejes estructurantes, cambios en la morfotipología del tejido urbano, hitos geográficos como ríos, quebradas o laderas con diferencias de nivel por la topografía del territorio, o bien, considerando la existencia de algún límite administrativo como los límites de las unidades vecinales o el propio límite urbano comunal.

Sin embargo, entendiendo que el deterioro físico y la vulnerabilidad social no necesariamente están asociados a divisiones administrativas específicas, metodológicamente se estableció que los límites operativos de una 'zona prioritaria' podrían estar compuestos por distintas unidades territoriales o elementos. Por ejemplo, una 'zona prioritaria' puede contener en su interior diversos barrios, servicios y equipamientos de distintas escalas, estar compuesta por una o varias unidades vecinales o bien, conformarse por sectores que correspondan a dos o más comunas, en tanto se trata de un territorio cuyas problemáticas van más allá de los límites administrativos.

Por ello, a la hora de definir los límites operativos de la 'zona prioritaria', éstos debían corresponder más bien a límites espaciales y funcionales que administrativos, identificándolos a partir de una decisión estratégica que apostara por su planificación integral.

Marcada por la vocación que representa, los límites operativos de una 'zona prioritaria' debían marcar claramente un cambio de percepción del interior respecto de su exterior, ya sea por el carácter estructural de alguno de sus bordes, porque se genera un cambio en la morfología del tejido urbano o bien, por el cambio en la dinámica que se percibe al traspasar sus límites.

\section{CARACTERIZACIÓN DE LA ZONA PRIORITARIA}

La configuración y el trabajo en 'zonas prioritarias' deja planteada una apuesta por la regeneración integral de una pieza urbana que aborde sus problemáticas desde una mirada interescalar que va desde la vivienda, el barrio, el entorno urbano a los barrios (la 'zona prioritaria') y la propia ciudad, 
FIGURA 4. FORMACIÓN DE 'ÁREA DE VULNERABILIDAD TERRITORIAL' PARA LAS CIUDADES DE ANTOFAGASTA, VALDIVIA, SAN ANTONIO Y SANTIAGO.
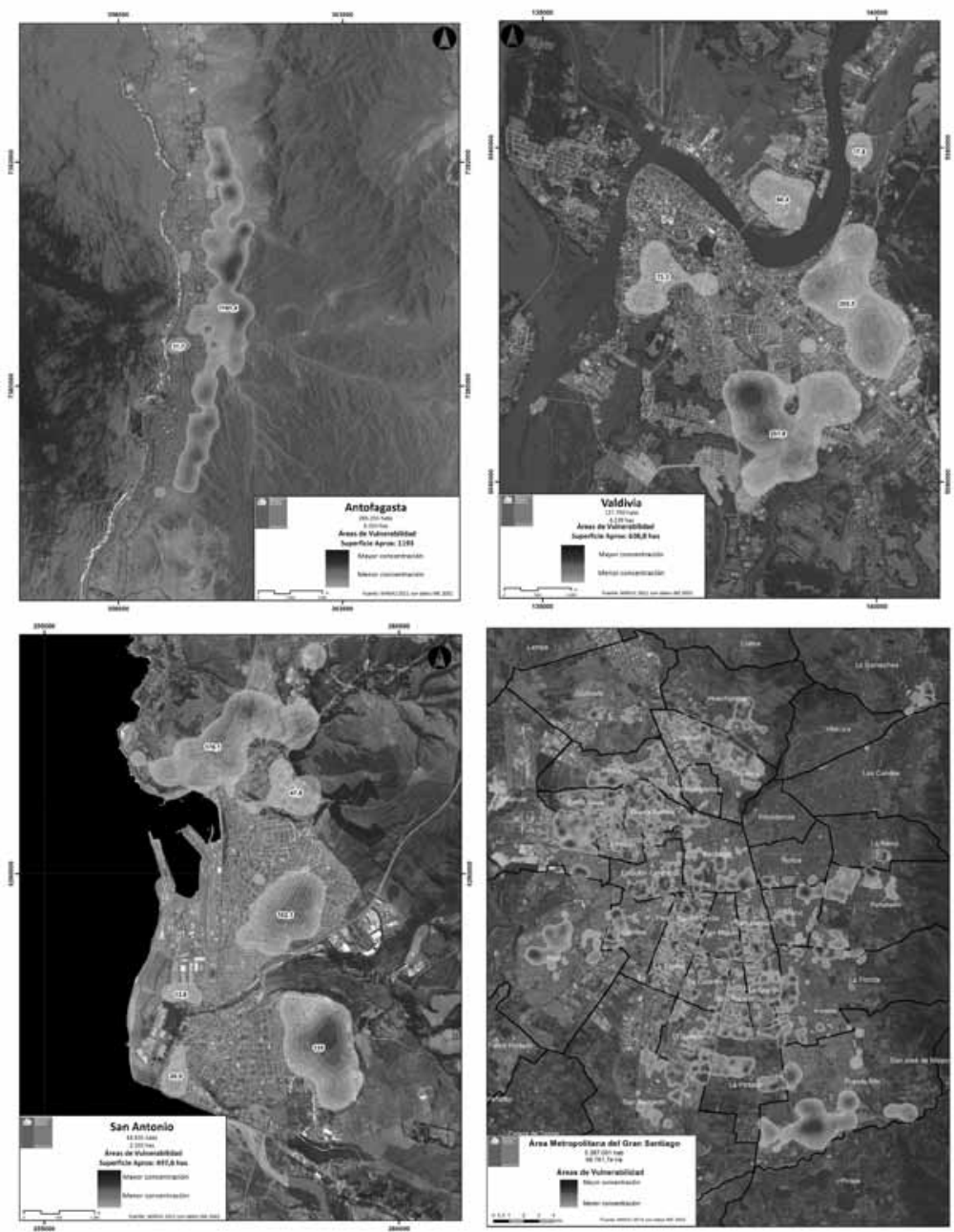

Fuente: Área de Estudios, Secretaría Ejecutiva de Desarrollo de Barrios. MINVU, 2011. 
así como desde una mirada intersectorial que logre articular los distintos sectores y actores que intervienen en el territorio.

Por ello, a la hora de definir sus límites operativos fue fundamental realizar previamente un diagnóstico y caracterización territorial del 'área de vulnerabilidad', identificando, además de sus requerimientos, aquellos elementos o hechos urbanos estratégicos que pudieran servir de insumo a una futura propuesta de regeneración urbana.

Realizar un análisis diagnóstico de caracterización permitió, por un lado, informarse acerca del escenario de la 'zona prioritaria', identificando, a partir de sus características de déficit, deterioro urbano y vulnerabilidad social, sus problemáticas y potencialidades de manera simultánea. Por otro lado, permitió entender su condición en la ciudad y conocer las transformaciones urbanas que se realizarán en su contexto a partir de los distintos instrumentos de planificación o las inversiones que se llevarán a cabo en ellas.

En efecto, la caracterización de la 'zona prioritaria' se desarrolló observando los distintos elementos y variables que existían en su interior, considerando las fortalezas o atributos que la componen como localización, tamaño, vocación urbana, económica, cultural, turística, etc., las problemáticas y oportunidades, las acciones e inversiones que se estén generando, así como la presencia de los distintos hechos urbanos que la singularizan del resto del territorio.

Es por esto que a la hora de configurar la 'zona prioritaria' no sólo fueron consideradas sus áreas de concentración de vulnerabilidad social y deterioro urbano, sino que también, dependiendo del caso, fueron considerados ciertos territorios sin urbanizar, áreas o sectores ya consolidados, áreas de conservación patrimonial o medioambiental, grandes artefactos, hitos geográficos, áreas de riesgo, etc. Desde una mirada estratégica, cada uno de estos elementos puede ser determinante en la planificación integral de la 'zona prioritaria' como pieza de actuación de escala urbana, colaborando en su consolidación.

\section{APLICACIÓN DE LA METODOLOGÍA}

A raíz de la diversidad de tipos de ciudades del país, tomando en cuenta la amplia gama de variables que develó el ejercicio metodológico, los resultados, aprendizajes y oportunidades que aparecieron son significativos.

Probablemente determinado por las políticas de vivienda de las últimas décadas, una vez desarrolladas las cartografías con el cruce de los 4 indicadores, interesante es consignar cómo, si bien las ciudades podían presentar uno o más sectores de vulnerabilidad, en muchos casos las áreas residenciales de bajo costo fueron las que expresaron 
FIGURA 5. CONFIGURACIÓN DE LA 'ZONA PRIORITARIA' PARA LA CIUDAD DE ARICA, A PARTIR DE LA DEFINICIÓN DE SUS LÍMITES OPERATIVOS.
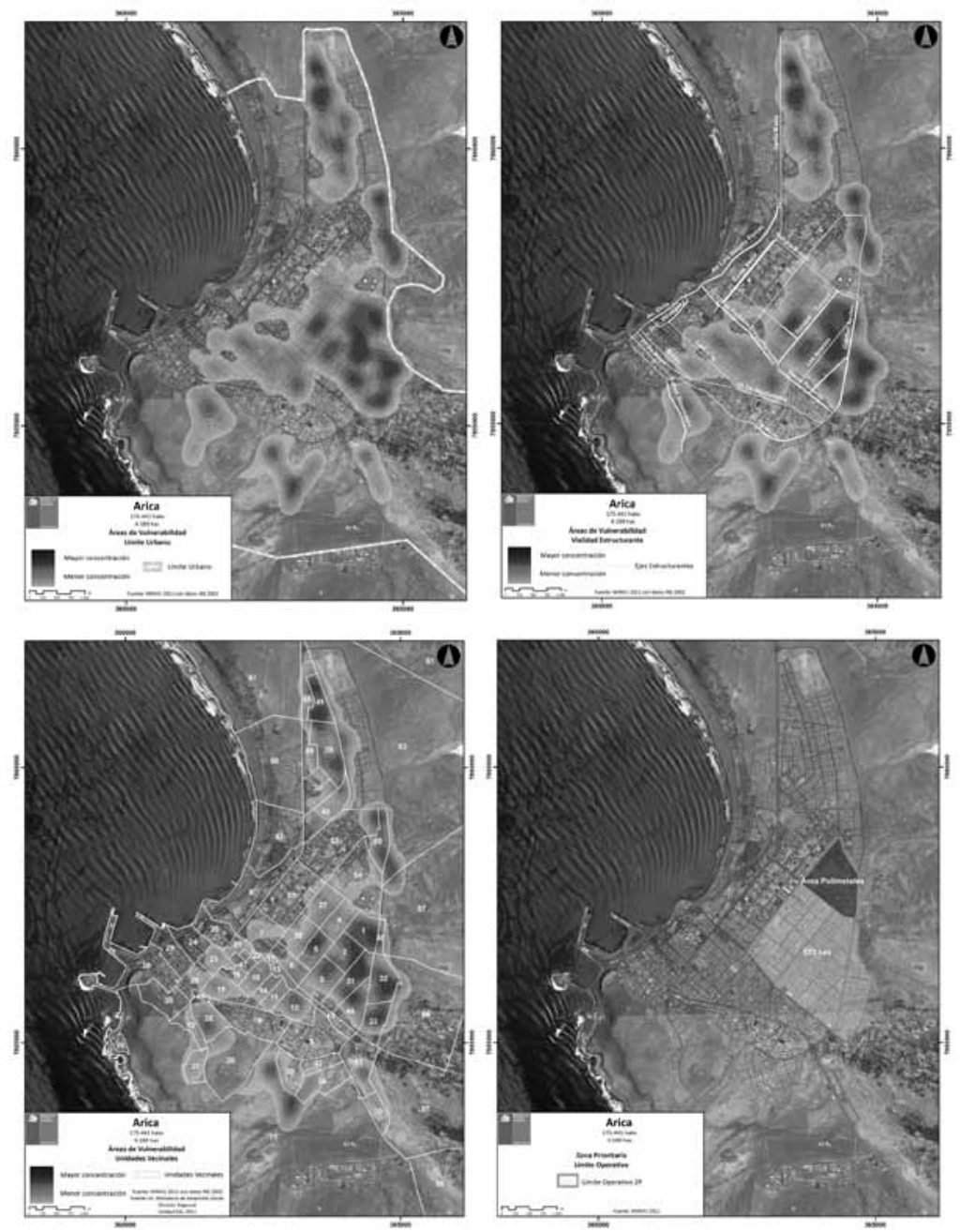

Fuente: Área de Estudios, Secretaría Ejecutiva de Desarrollo de Barrios. MINVU, 2011. 
una formación concentrada del deterioro, a través de un continuo espacial y homogéneo bastante compacto.

Bajo esta realidad, la aplicación de la metodología de focalización viene a constatar prácticamente los mismos territorios a los cuales se han aproximado otros estudios basados en el mismo objetivo ${ }^{31}$, coincidiendo también de manera similar con sectores que, planteados en escalas menores y bajo otros enfoques, ya habían sido identificados previamente desde estudios que han girado en torno a la noción de segregación residencial.

Si bien la finalidad de la metodología usada por MINVU y la usada por Atisba es similar, la principal diferencia radica en las escalas del fenómeno que buscan representar, diferenciándose en la operatoria utilizada para la aproximación, así como en la capacidad de poner límites al territorio. De esta forma, mientras Atisba promedia sus datos en "n" polígonos definidos previamente por el consultor, la metodología MINVU, a partir de la conformación de las 'áreas de vulnerabilidad' como un continuo espacial, configura las 'zonas prioritarias' como resultado de la caracterización del territorio.

31 Se puede señalar en esta línea el estudio "Guetos en Chile", el cual, a partir de 4 criterios urbanos y sociales que poseen diferentes escalas de representación en el territorio, busca identificar los territorios de vulnerabilidad para 22 ciudades del país (Atisba, 2010).
Sin embargo, vale la pena destacar que uno de los principales atributos de la metodología radica en la posibilidad de configurar las 'zonas prioritarias' como unidades de gestión urbana de escala intermedia, desde de la caracterización de los territorios. En consecuencia, como resultado de criterios objetivos, la metodología permite por un lado aproximarse a la vulnerabilidad, favoreciendo en segunda instancia, como resultado de un análisis cualitativo, configurar las unidades de gestión a partir de la realidad del territorio, considerando elementos o hechos urbanos que muchas veces ni los indicadores ni los límites administrativos pueden visualizar.

Bajo este principio, dentro de los resultados que arrojó la aplicación metodológica, ciertas 'zonas prioritarias' se configuraron por la existencia fragmentada de sectores con déficit y deterioro urbano que convivían con áreas con un mayor nivel de consolidación urbana. Esta situación fue contemplada, en tanto plantea la posibilidad de apostar por una mirada estratégica que favoreciera la continuidad del tejido urbano, iniciando así el proceso de acabado urbano y consolidación de esa pieza desde la integración de cada uno de sus fragmentos. 


\section{FIGURA 6. ZONAS PRIORITARIAS PARA PADRE LAS CASAS Y ALTO HOSPICIO.}

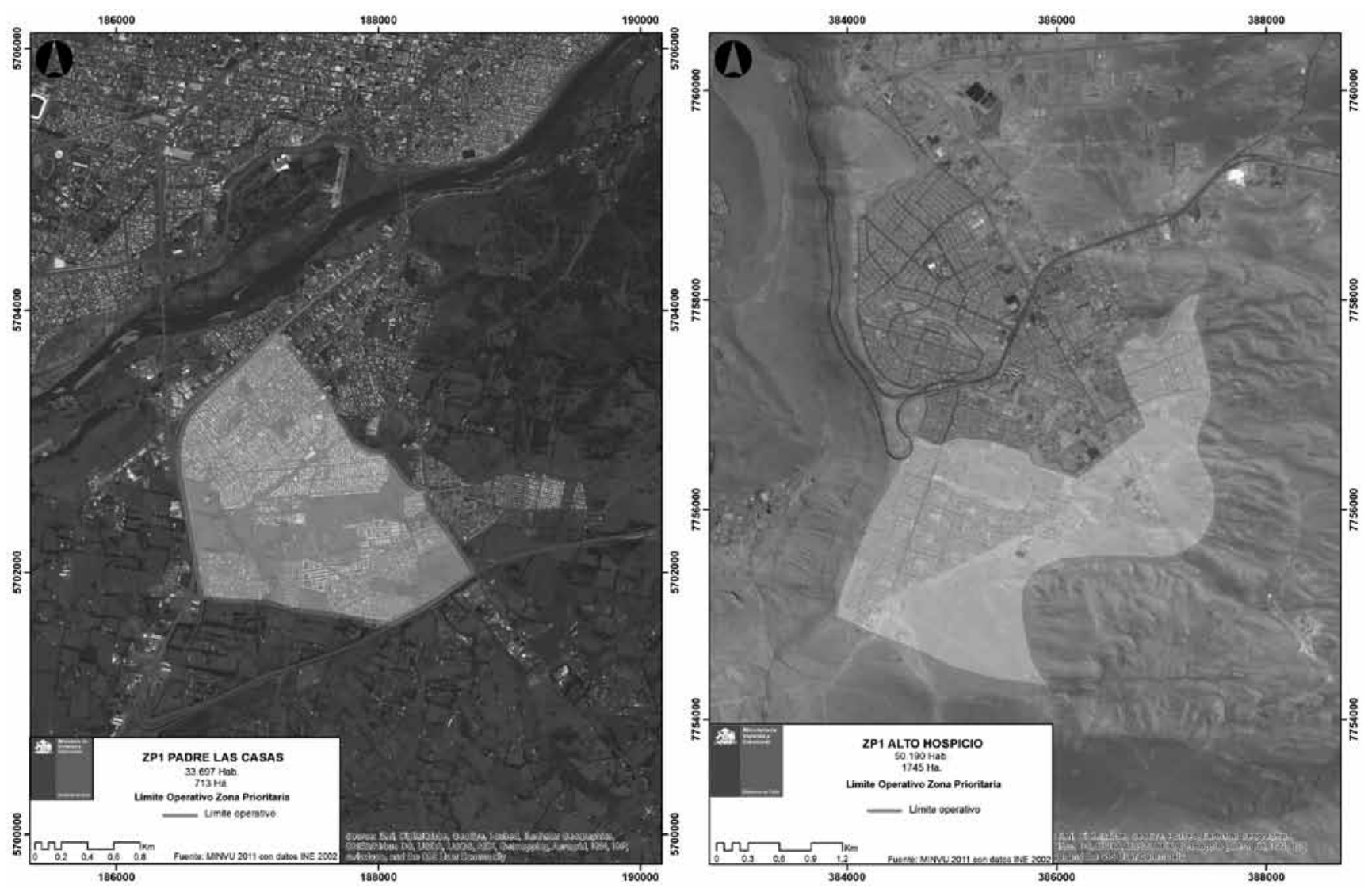

Fuente: Área de Estudios, Secretaría Ejecutiva de Desarrollo de Barrios. MINVU, 2011. 


\section{FIGURA 7. ZONA PRIORITARIA PARA LA CIUDAD DE IQUIQUE.}

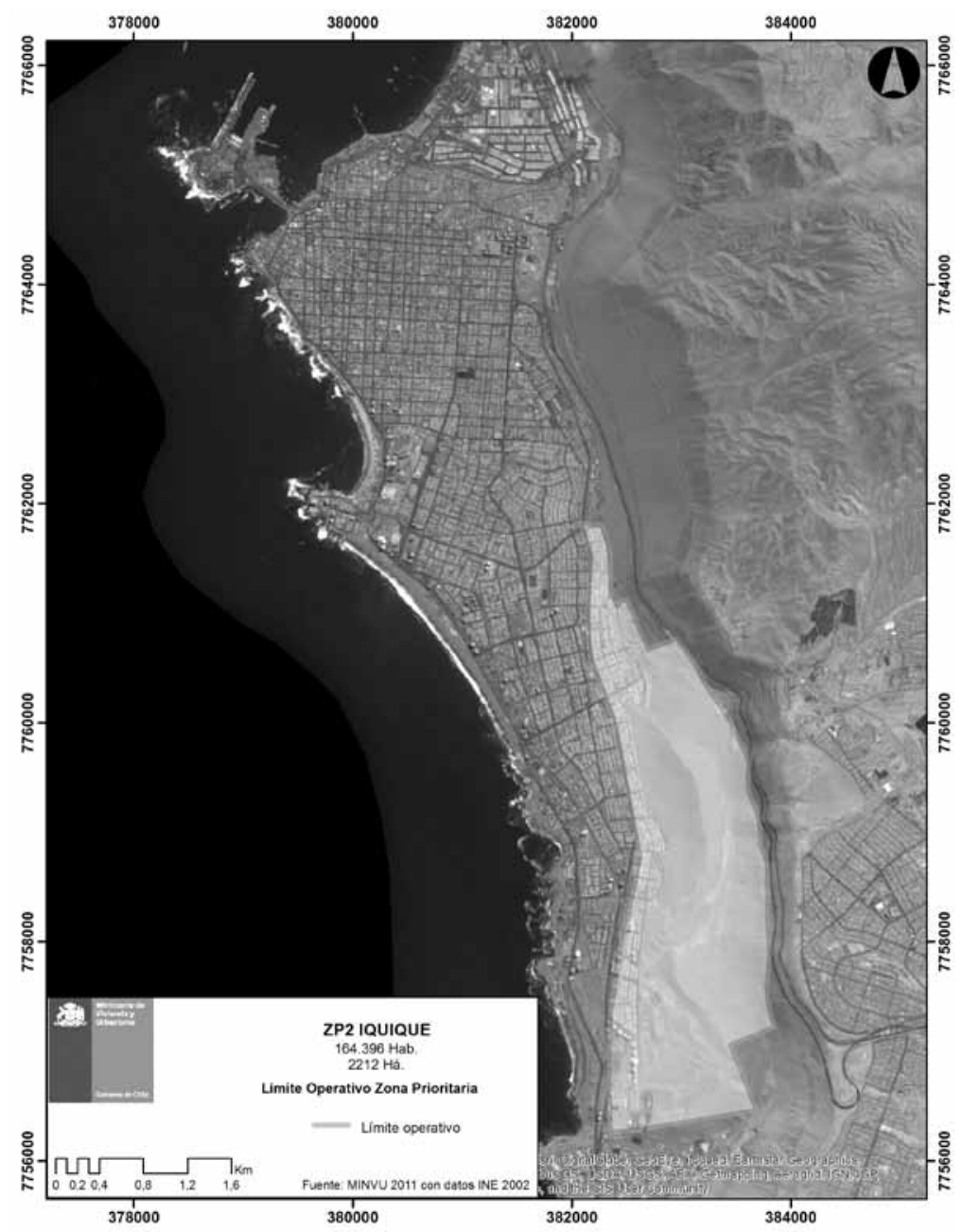

Fuente: Área de Estudios, Secretaría Ejecutiva de Desarrollo de Barrios. MINVU, 2011. 
Asímismo, como consecuencia del crecimiento fragmentado de las ciudades, se pudieron identificar aquellos vacíos o sectores a los que aún no llega la mancha urbana. Aunque en muchos casos éstos aún no están urbanizados, desde una perspectiva de planificación estratégica e integral se consideró integrar estas áreas al interior de la 'zona prioritaria', entendiéndolas como áreas dispuestas para el crecimiento urbano. Desde esta perspectiva, bajo la definición de la 'zona prioritaria' como una unidad de gestión de escala intermedia, con dichos vacíos se presenta la oportunidad de iniciar procesos de 'acabado urbano' en su interior, así como la posibilidad de aceptar proyectos de escala urbana como potencial de desarrollo, colaborando en su consolidación y en revertir los procesos de deterioro.

Interesante en esta línea es exponer el caso de Arica (figura 5), en el cual, a la hora de configurar la 'zona prioritaria', se consideró la incorporación de un área significativa de contaminación por poli métales adyacente -que está siendo intervenida por otro programa ministerial-, con la intención de realizar una solución integral. A su vez, el caso de Padre las Casas (figura 6) da cuenta cómo la 'zona prioritaria', contempló una serie de tejidos fragmentados y vacíos urbanos de un área de crecimiento de la ciudad, configurando sus límites desde un eje estructurante en el sector nor-poniente hasta el límite urbano. En el caso de Alto Hospicio (figura 6) fue considerado el límite urbano del sector sur-oriente de la ciudad como uno de sus límites operativos, incorporando un sector que aún no ha sido urbanizado. Desde el punto de la planificación de la 'zona prioritaria' como pieza urbana integral, su consideración presenta la oportunidad de pensar un equipamiento o servicio de escala urbana que a futuro se localice ahí, logrando simultáneamente su articulación al momento de planificar las nuevas áreas residenciales del crecimiento urbano.

Desde una mirada territorial fue interesante también la identificación estratégica de hitos geográficos, con el objetivo de ser potenciados por la planificación integral de la 'zona prioritaria'. Aparecen así ciertos casos en que la presencia de un río al interior de una 'zona prioritaria', o la presencia de un borde de cerro o quebradas fueron considerados como posibles intervenciones de escala urbana en tanto podrían concebirse como elementos vertebradores.

El caso de Iquique es interesante desde este punto de vista, en tanto la configuración de la 'zona prioritaria' incorpora el Cerro Dragón, importante santuario de la naturaleza de la ciudad (figura 7). En este caso, la problemática estuvo centrada en el encuentro del tejido urbano residencial con el borde del cerro, que, constituido como una gran duna, ha desarrollado un significativo y permanente avance hacia diversos sectores residenciales, determinando zonas con un alto deterioro por el abandono y falta de cuidado de éstas. Este hecho, 
FIGURA 8. ZONA PRIORITARIA PARA LA CIUDAD DE IOUIOUE. PROPUESTA DE ARTICULACIÓN ENTRE EL TEJIDO URBANO Y EL BORDE DEL CERRO.

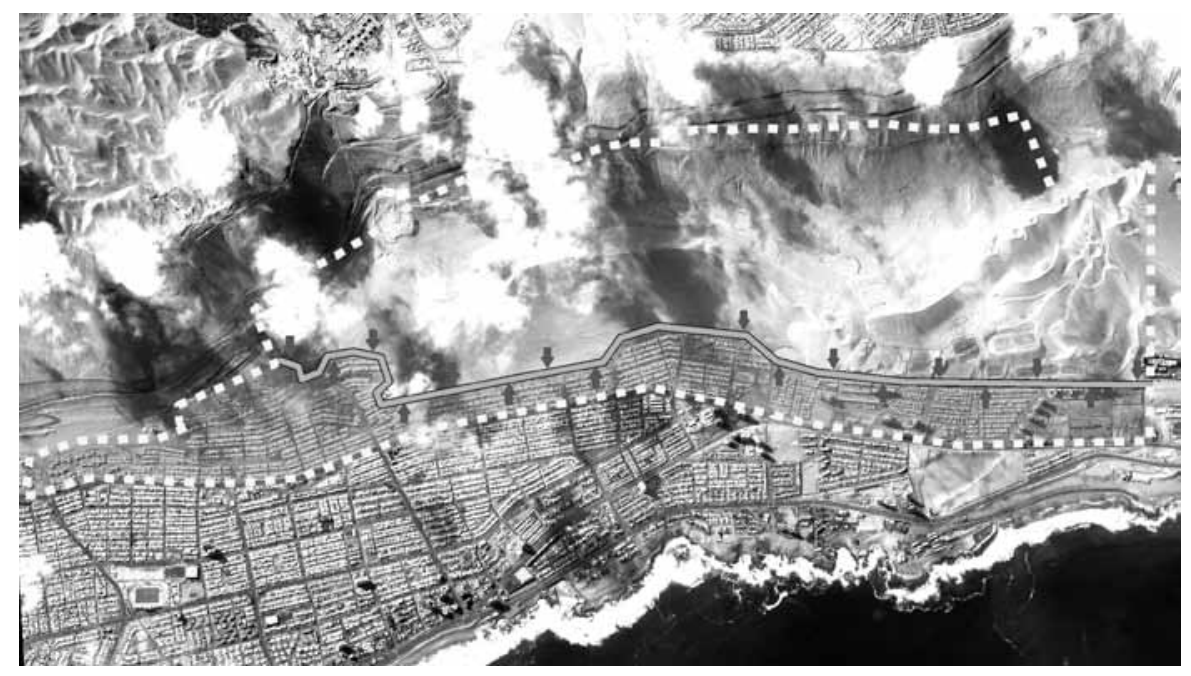

Fuente: Área de Estudios, Secretaría Ejecutiva de Desarrollo de Barrios. MINVU, 2012.

sin embargo, se transformó en oportunidad de proyecto al incorporar la gran duna dentro de la 'zona prioritaria', en tanto a nivel de propuesta se plantea la posibilidad de que, a través de un proyecto de escala urbana de carácter central y longitudinal al polígono, éste se transforme en bisagra del encuentro entre el tejido residencial y el área de protección, proponiendo, por ejemplo, un paseo recreativo, una ciclovía, etc., que logren separar pero al mismo tiempo articular ambos sectores (figura 8).
En otro ámbito, a partir del ejercicio de localización de los barrios y condominios sociales en los que ya se encontraba operando el programa, la focalización territorial demostró que en la mayoría de los casos éstos estaban localizados en las 'áreas de vulnerabilidad territorial', emplazados, casi siempre, al interior de 'zonas prioritarias' (figuras 9 y 10).

Este ejercicio resultó interesante al entender la 'zona prioritaria' como pieza urbana de 
FIGURAS 9 Y 10. GEORREFERENCIACIÓN DE LOS DISTINTOS PLANES Y PROGRAMAS EN EL TERRITORIO URBANO Y EN LA 'ZONA PRIORITARIA' DE ARICA Y TALCAHUANO.
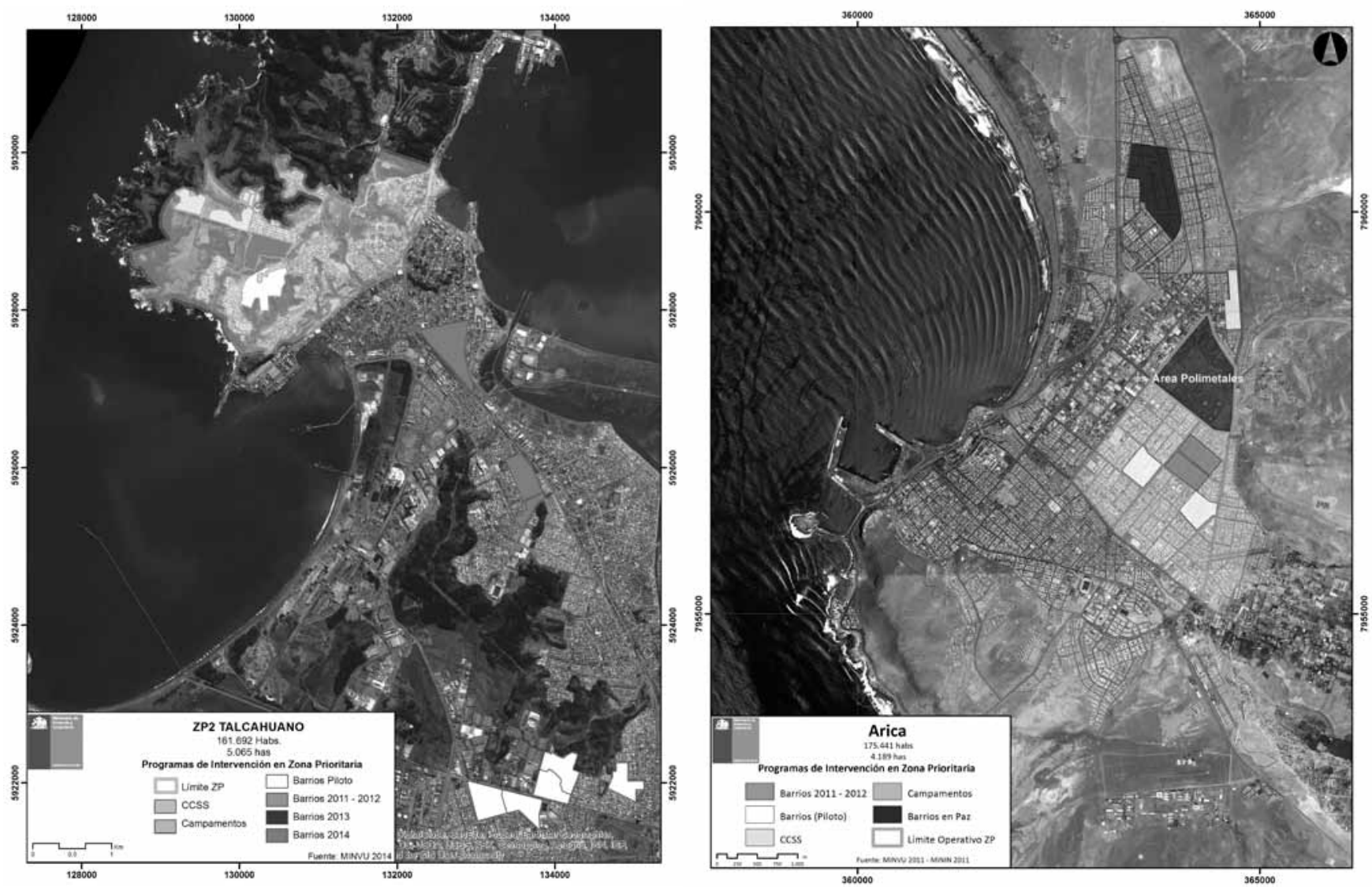

Fuente: Área de Estudios, Secretaría Ejecutiva de Desarrollo de Barrios. MINVU, 2012. 
intervención integral y unidad de gestión urbana de escala intermedia entre el barrio y la ciudad, en tanto cualquier acción realizada dentro de sus límites operativos podrá tener un efecto sinérgico en otros puntos y en relación con otras inversiones, ya sea en los barrios ya atendidos por el programa, los nuevos barrios a intervenir, los condominios sociales candidatos para la actual línea de atención o cualquier acción que se lleve a cabo, ya sea en la escala urbana o en la escala barrial.

Esta posibilidad da cuenta de la oportunidad que entrega la 'zona prioritaria' como pieza urbana de escala intermedia, al permitir y favorecer la intersectorialidad y la interescalaridad, observando en los distintos casos cómo logra transformarse en una plataforma de articulación al georreferenciar las distintas acciones e inversiones que se desarrollan en ella.

\section{Reflexiones finales}

A diez años de la implementación del Programa de Recuperación de Barrios se puede constatar un fuerte proceso de consolidación de la escala barrial como unidad de intervención territorial, a partir de lo cual han surgido nuevos desafíos.

Entendiendo que no todas las problemáticas de los barrios están en su interior, sino que muchas de ellas tienen que ver con la escala urbana y la estructura espacial de las ciudades, dentro de esos nuevos desafíos se evidencia la necesidad de abordar el deterioro y el déficit urbano de los barrios más allá de sus propios límites.

Si bien en primera instancia la conformación de 'zonas prioritarias' tuvo el objetivo de construir una herramienta adecuada que permitiera la focalización territorial para la selección de los barrios del programa, a partir de los criterios desarrollados para la definición de sus límites operativos, la metodología nos ha develado un abanico de oportunidades que, centradas en el desafío de avanzar en la equidad y la integración urbana, podrán contribuir en acercar los beneficios de la ciudad a zonas que estructuralmente han quedado lejos de ésta.

Desde este punto de vista, a la luz de los resultados, el gran valor en la definición de una 'zona prioritaria' radica en la posibilidad de configurar una unidad de gestión urbana de escala intermedia que logre trabajar estratégicamente entre el barrio y la ciudad. En este sentido, la 'zona prioritaria' como pieza urbana de escala intermedia tensiona la posibilidad y entrega la oportunidad de ser regenerada integralmente abordando sus diversas problemáticas desde una mirada interescalar, intersectorial y estratégica del territorio.

De aquí que lo más significativo a la hora de definir una 'zona prioritaria' estará en considerar la capacidad de cada uno de sus elementos urbanos para generar sinergias y atraer recursos que permitan combatir y detener el deterioro urbano existente, 
iniciando un proceso efectivo de regeneración global y sostenible en el tiempo.

Considerada como una unidad de gestión territorial de alta prioridad pública, la 'zona prioritaria' presenta la oportunidad de realizar un trabajo de coordinación en todos los niveles, para lo que se propone la idea de formular 'planes estratégicos de acción concertada', que articulen y programen la participación de todos los actores involucrados en esa escala. A través de acuerdos que programen jerárquicamente las acciones, las inversiones y la articulación entre éstos al interior de la 'zona prioritaria', el desarrollo de un 'plan estratégico de acción concertada' permitirá abordar los procesos de regeneración urbana considerando las problemáticas y sus soluciones mediante una planificación coordinada de las acciones sectoriales, multisectoriales $u$ otras que pudieran converger.

Este objetivo plantea entonces la necesidad de entender la ciudad desde una planificación transversal que considere la existencia de los diversos instrumentos de planificación así como las inversiones realizadas o por realizar, en una apuesta real de articulación al momento de ejecutar las distintas intervenciones en el territorio. Emprender una acción concertada de actores, focalizados en una unidad específica del territorio como es la 'zona prioritaria', se presenta como un concepto de 'planificación estratégica' potenciando así "la sinergia a través de los vínculos y superposiciones entre programas y proyectos, minimizando a través de la planificación los efectos no deseados de los programas"32. Por ello, la importancia de la metodología como herramienta de focalización territorial en la gestión urbana, al permitir cuantificar y tomar decisiones respecto de los territorios donde debemos intervenir, dimensionando y jerarquizando sus necesidades según las urgencias identificadas.

Desde otra perspectiva, valorando la definición de las 'zonas prioritarias' como unidades de gestión de menor escala que la totalidad del territorio urbano, clave es también la posibilidad de alcanzar niveles más cercanos de participación ciudadana, llegando de mejor manera a involucrar a sus habitantes. Este hecho podrá colaborar finalmente en la sostenibilidad de nuestras ciudades, apostando a

32 Referido a la formulación del LUDA (Large Urban Distressed Areas), los autores señalan que debe ser entendido como concepto de gobernanza y como instrumento de gestión cuyo objetivo es concitar la atención pública en torno a la necesidad de mejorar la coordinación en un nivel más amplio que las estrategias tradicionales de renovación urbana (Schiappacasse y MüIler, op. cit., p. 8). 
hacer más efectiva la participación en la construcción de los espacios públicos.

Entendiendo que la integración de las áreas que concentran vulnerabilidad física y social pasa en muchos casos por soluciones de carácter estructural que logren igualar la calidad urbana de estos territorios respecto a otras zonas de la ciudad, la metodología nos permitirá avanzar en la rehabilitación integral de éstos mediante la consolidación de espacios públicos de calidad y la dotación de equipamientos de manera equilibrada. En consecuencia, la 'zona prioritaria' como unidad de intervención intermedia entre el barrio y la ciudad plantea la oportunidad de abordar su regeneración a través de proyectos de escala urbana colaborando en los procesos de integración, acabado y consolidación urbana.

Cuando hablamos de proyectos de escala urbana nos referimos a un parque, la formación de un área de centralidad, la llegada de una estación de metro, la construcción de un centro cívico, etc., en definitiva, proyectos de impacto mayor que articulen la fragmentación y el tejido urbano inconcluso, consolidando las áreas de concentración de pobreza e integrándolas al resto de la ciudad.

Podemos decir entonces que la importancia que tiene la configuración de 'zonas prioritarias' como unidades de escala intermedia está en la posibilidad de ser soporte de proyectos de escala urbana. Podremos entender así el proyecto de escala urbana como un elemento de integración urbana, en tanto a través de la inversión de obras de escala e impacto mayor se favorecerá de manera efectiva la inclusión y la cohesión social de nuestras ciudades.

Desde la planificación urbana, este mecanismo pasa a ser fundamental pues el trabajo por medio de 'zonas prioritarias' permitirá ir consolidando priorizadamente el territorio mediante la intervención de piezas urbanas de manera integral. El trabajo integral y estratégico al interior de cada 'zona prioritaria' podrá colaborar en frenar el crecimiento extensivo de la ciudad, al identificar áreas de interés y oportunidad ya sea para su densificación o para la utilización de los vacíos urbanos con equipamiento, vivienda, áreas verdes, etc., permitiendo así entregar continuidad al tejido urbano a partir del acabado urbano del territorio.

Finalmente, importante es señalar que si bien en esta ocasión como primera experiencia se trabajó con una gama acotada de indicadores, de los resultados que arroje un nuevo censo quedará planteado el desafío de actualización del presente ejercicio metodológico, con la expectativa de avanzar simultáneamente en la incorporación de otras variables que tienen una clara expresión territorial. En consecuencia, en el marco de la investigación urbana y la construcción de instrumentos de planificación territorial, la metodología nos plantea el desafío de seguir indagando en el trabajo con indicadores 
urbanos, sistemas de información geográfica y la definición de estándares.

\section{Bibliografía}

ALCALÁ Consultores. Informes 1 y 2 estudio evaluación del Programa Quiero mi Barrio: una propuesta metodológica. Programa de Recuperación de Barrios. Santiago de Chile, Ministerio de Vivienda y Urbanismo. Noviembre 2010.

ATISBA. Guetos en Chile: reporte. [En línea]. Atisba. 2010. [Fecha de consulta: 26 octubre 2012]. Disponible en: http://atisba.cl/wp-content/ uploads/2011/06/Reporte_Guetos_en_Chile2010.pdf.

BUSTOS, Mónica. Cantidad y bajos costos como factores en la edificación masiva: 2do. período: 1979-2004. En: EL PROYECTO residencial en baja altura como modelo de crecimiento urbano. Santiago de Chile y su política de vivienda en el último cuarto de siglo. Barcelona, España, Universidad Politécnica de Catalunya. 2006. p. 151171. Tesis de doctorado en urbanismo y ordenación territorial.

CASTEL, Robert. De la exclusión como estado a la vulnerabilidad como proceso. [En línea]. 1995. [Fecha de consulta: 26 febrero 2016]. Disponible en http://www.dwvalencia.com/claver/Documentos/ exclusion(robert_castel).pdf.

DIRECCIÓN de Presupuestos. Evaluación programas gubernamentales (EPG). Programa Recuperación de Barrios (Quiero Mi Barrio). [En línea]. DIPRES. Agosto 2010. 14 p. Disponible en: http://www.dipres.gob.cl/574/articles-64138_doc_pdf.pdf.

GIMÉNEZ, Pilar, ed. y UGARTE, José Ramón, ed. Política nacional de desarrollo urbano: ciudades sustentables y calidad de vida. PNUD, MINVU. 2014. ISBN 978-956-9432-05-7.

JEREZ, Carlos. La docencia en el urbanismo de la escuela de Granada. En: LOPÉZ, Antón, ed. y GOIKOETXEA, Koldo, ed. Un urbanismo docente. San Sebastián, España. Servicio Editorial de la Universidad del País Vasco. 2008. p. 95-108. ISBN 978-84-9860-297-5.

MINISTERIO de Vivienda y Urbanismo. Programa de Recuperación de Barrios. [En línea]. MINVU. 2009. [Fecha de consulta: 13 abril 2001]. Disponible en: http://www.minvu.cl/opensite_20070212164909. aspx.

RODRÍGUEZ, Alfredo y SUGRANYES, Ana. El problema de vivienda de los "con techo". En: RODRIGUEZ, Alfredo, ed. y SUGRANYES, Ana, ed. Los con techo: un desafío para la política de vivienda social. Santiago de Chile, SUR. 2005. p. 61-80. ISBN 956-208-074-9.

SAMOL, Frank. Consulting BUS. Asesoramiento a Corto Plazo: Experiencias Internacionales en la Formulación de Políticas Públicas de Recuperación de Barrios. Informe de la misión del 2 al 6 de junio de 2008. Proyecto del Fondo de Reformas "Política Pública en Recuperación de Barrios", MINVU, Chile, comisionado por GTZ. MINVU, Chile. Dresde, junio de 2008. 
SCHIAPPACASSE, Paulina y MÜLLER, Bernhard. El deterioro urbano en grandes áreas urbanas europeas. Aproximaciones teóricas y metodológicas. Urbano. 11(18): 82-91, noviembre 2008. ISSN 0717-3997.

SOLÁ-MORALES, Manuel de. Un campo de cosas urbanas. En: LOPÉZ, Antón, ed. y GOIKOETXEA, Koldo, ed. Un urbanismo docente. San Sebastián, España. Servicio Editorial de la Universidad del País Vasco. 2008. p. 121-131. ISBN 978-84-9860-297-5.

SUR PROFESIONALES. Estudio, seguimiento y análisis institucional del Programa Recuperación de Barrios. Informe ejecutivo. 2009. p. 1-25. 